\title{
Prevalence survey for chronic rheumatic heart disease and rheumatic fever in northern India
}

\author{
J. N. Berry \\ From the Department of Cardiology, Postgraduate Institute of Medical Education and Research, \\ Chandigarh, India
}

A house-to-house survey of a random sample of 33,36I subjects, comprising one-third of the total population of a town in northern India, shows the prevalence of chronic rheumatic heart disease and rheumatic fever to be $1 \cdot 23 / 1000$ among male and 2.07/1000 among female subjects. Of the 48 cases of rheumatic heart disease, 62 per cent gave a history suggestive of rheumatic fever in the past. Six of these had rheumatic activity. No cases were seen below the age of 5 years and above the age of 50. One-quarter of the cases of mitral stenosis and half the cases of mitral incompetence in both sexes were below the age of 20 years All the women and 84 per cent of the men with rheumatic heart disease had mitral valve involvement, while the aortic valve was involved in 42 per cent of men and 14 per cent of women. Mitral stenosis and mitral incompetence were equally common, singly or mixed, while aortic incompetence was the usual aortic lesion. Pure mitral stenosis was $3 \frac{1}{2}$ times commoner and mitral incompetence twice as common in female than in male subjects. Among women, mitral stenosis developed earlier in many and was more often complicated by pulmonary hypertension. Previous published data, based on hospital figures alone, have given rise to the mistaken belief that it is less common among women in India and other Eastern countries. It is probable that many of the other peculiarities of the disease like infrequency of chorea, subcutaneous nodules, lone mitral incompetence, and rheumatic fever as compared to rheumatic heart disease are also due to dependence on figures from teaching hospitals and specialized units which are biased by preselection.

The survey has uncovered a large reservoir of the disease among women requiring urgent measures for its detection, prevention, and treatment. A plea is made to liberalize fones' criteria for early diagnosis and start of chemoprophylaxis of rheumatic fever.

Figures published from various centres in India, based on hospital data, have suggested that, contrary to experience in many western countries, rheumatic heart disease and mitral stenosis are more common in men than in women in India. However, a house-to-house, total population survey to find cases of chronic rheumatic heart disease and rheumatic fever in a randomly selected sample of 33,361 persons involving one-third of the urban population of Chandigarh, a town in northern India, showed that the disease was more common in women, in the young, and in the poor socioeconomic groups. The results of this survey and their implications are briefly discussed here.

\section{Material and methods}

Chandigarh is a newly built town, about 18 years old, situated $30^{\circ} .43^{\prime} \mathrm{N}$ and $76^{\circ} .47^{\prime} \mathrm{E}$, at the foot of the Siwalik hills, at a height of 314 metres. The Received I5 March I97I. average yearly rainfall is $106 \mathrm{~cm}$, mostly during the monsoon from July to September. The temperature varies from a maximum of $44^{\circ} \mathrm{C}$ during summer to a minimum of $2-3^{\circ} \mathrm{C}$ during winter, with a good deal of day to night difference throughout the year.

Chandigarh, joint capital of the States of Punjab and Haryana, has been conceived and built as a well-planned town, divided into 30 sectors ( 17 more are being added), each $\frac{1}{2}$ by $\frac{3}{4}$ mile but varying in population density from 5000 to 25,000 . More than one-half of the houses in the town have been built by the government for its own staff. Each sector was built as a self-sufficient community unit with its own shopping centre, park, and schools. The houses for the lowest category staff were planned to provide at least two living rooms for a family. But considerable overcrowding has developed, much more than was ever intended to be permitted, in the lower socioeconomic groups, because of paucity of cheap housing accommodation. Yet, the town is cleaner and more sanitary than most towns in India.

The population, consisting mostly of displaced 
persons from West Pakistan, is of mixed racial stock as in other parts of the north Indian States of Punjab and Haryana. There is no large industrial population and the government and semigovernment agencies are the biggest employers.

At the beginning of the survey, in the middle of 1966, the town was estimated to have a population of about 100,000 . In order to get a large enough and representative sample, it was decided to examine one-third of the total population of the town. After excluding the obviously unsuitable sectors like sector I which consists of the Secretariat, Legislatures, and High Court, Sector I2, consisting of Postgraduate Medical Institute (P.G.I.) and its hospital, and Sector I4, consisting of the Punjab University, sectors for the survey were randomly chosen. In the first sector surveyed, inmates of all the houses were examined but, in the rest of the sectors, in order to spread the sample over a wide part of the town, only alternate homes were studied. The sectors studied were $15,18,20,22$, and 23.

The field team consisted of a social worker and a doctor. The social worker visited each home, established rapport with the family, explained the purpose of the survey, recorded the socioeconomic history, and arranged an appointment for the doctor at a time convenient to the family, when both visited the home. Each member of the household was examined. Any history of sore throats or one suggesting rheumatic fever in the past was recorded on a proforma prepared by the Cardiovascular Group of the Indian Council of Medical Research. Often, more than one visit was necessary to examine all the members. Those found with a history suggestive of rheumatic fever or signs of any heart disease were referred to the author at the P.G.I. Hospital where they were reexamined and a chest $x$-ray and a I2-lead electrocardiogram taken. Those who refused to come to the hospital despite repeated requests by the field team were examined by the author in their homes.

Rheumatic fever and chronic rheumatic heart disease were diagnosed according to the definition and criteria as defined by the World Health Organization (I966). The survey was completed over a period of $3 \frac{1}{2}$ years.

\section{Results}

The total population examined consisted of 33,36I persons, 17,928 male and 15,433 female. Table I shows the age and sex distribution of this sample. The number of cases with rheumatic heart disease or only a history of rheumatic fever are shown in parentheses.

Of the 54 subjects diagnosed as such, one male and one female subject, each in the 15 to 20 year age-group, one man and one woman, each 27 years old, one boy aged $6 \frac{1}{2}$ years, and one woman aged 45 years gave only a history suggestive of rheumatic fever in the past. There were no cardiac signs at the time of examination. Except for the child who gave only
TABLE I Frequency distribution of the total population sample according to age and sex with numbers of cases of rheumatic fever and rheumatic heart disease in each group (in parentheses)

\begin{tabular}{lrrr}
\hline Age $(y r)$ & Male & Female & Total \\
\hline $0-5$ & $2631(-)$ & 236 I (-) & $4992(-)$ \\
$5 \cdot 1-10$ & $2185(2)$ & $2036(2)$ & $4221(4)$ \\
IO.I-15 & $1911(5)$ & $1772(5)$ & $3683(10)$ \\
I5.1-20 & $2026(3)$ & $1829(7)$ & $3855(10)$ \\
$20 \cdot 1-30$ & $4355(8)$ & $3654(10)$ & $8009(18)$ \\
$30 \cdot 1-40$ & $2456(1)$ & $1866(5)$ & $4322(6)$ \\
$40 \cdot 1-50$ & $1308(3)$ & $969(3)$ & $2277(6)$ \\
Above 50 & $1056(-)$ & $946(-)$ & $2002(-)$ \\
Total & $17,928(22)$ & $15,433(32)$ & $33,361(54)$ \\
Prevalence & & & \\
per I000 & $1 \cdot 23$ & $2 \cdot 07$ & $1 \cdot 62$ \\
\hline
\end{tabular}

a history of chorea and recurrent sore throats, all satisfied modified Jones' criteria with a history of one or more attacks of polyarthritis and polyarthralgia with fever and recurrent sore throats in two. The remaining 48 subjects showed signs of rheumatic heart disease with mitral and/or aortic valvular involvement. The prevalence of rheumatic heart disease and rheumatic fever among male subjects was I.23 per thousand and among female subjects, 2.07 per thousand, considering all ages together.

Of 48 subjects with rheumatic heart disease, 30 gave a history suggestive of rheumatic fever in the past. The commonest combination was fever with polyarthritis and/or polyarthralgia present in all but one who gave a history of chorea alone. Chorea had been seen in 4 others and subcutaneous nodules in 3 .

Table 2 shows the valvular lesions present in those with rheumatic heart disease.

This shows a prevalence of rheumatic heart disease of 1.44 per thousand for the total population, being $\mathrm{r} \cdot 06$ per thousand among men and $\mathrm{I} .88$ per thousand among women. Pure mitral stenosis was three times as common and mitral incompetence twice as common in women as in men. The difference would have been still greater if the number of women in the sample was as large as the number of men. Mitral valve involvement was present in all the women with rheumatic heart disease, and the 3 cases with involvement of aortic valve alone -2 with aortic incompetence and one with aortic stenosis with aortic incompetence - were all men. Including the mixed lesions, Io men had mitral incompetence against 15 women. The corresponding figures for mitral stenosis were 8 and I5, respectively. Aortic incompetence, much less common than mitral valve disease, was commoner among men than among women (8 and 
TABLE 2 Type of valvular lesion in cases of rheumatic heart disease detected in the survey

\begin{tabular}{|c|c|c|c|c|c|c|c|c|}
\hline $\begin{array}{l}\text { No. of } \\
\text { subjects } \\
\text { examined }\end{array}$ & $\begin{array}{l}\text { Mitral } \\
\text { stenosis }\end{array}$ & $\begin{array}{l}\text { Mitral } \\
\text { incom- } \\
\text { petence }\end{array}$ & $\begin{array}{l}\text { Mitral } \\
\text { stenosis } \\
\text { with } \\
\text { mitral } \\
\text { incom- } \\
\text { petence }\end{array}$ & $\begin{array}{l}\text { Mitral } \\
\text { stenosis } \\
\text { with } \\
\text { aortic } \\
\text { incom- } \\
\text { petence }\end{array}$ & $\begin{array}{l}\text { Aortic } \\
\text { incom- } \\
\text { petence } \\
\text { with } \\
\text { mitral } \\
\text { incom- } \\
\text { petence }\end{array}$ & $\begin{array}{l}\text { Aotric } \\
\text { incom- } \\
\text { petence } \\
\text { alone }\end{array}$ & $\begin{array}{l}\text { Aortic } \\
\text { incom- } \\
\text { petence } \\
\text { with } \\
\text { mixed } \\
\text { lesions }\end{array}$ & $\begin{array}{l}\text { Total } \\
\text { with } \\
\text { rheumatic } \\
\text { heart } \\
\text { disease }\end{array}$ \\
\hline Male $(17,928)$ & 4 & 7 & 一 & 2 & - & 2 & 4 & 19 \\
\hline Female (15,433) & 12 & 12 & I & 2 & 2 & 一 & - & 29 \\
\hline Total $(33,36 \mathrm{I})$ & I6 & 19 & $\mathbf{I}$ & 4 & 2 & 2 & 4 & 48 \\
\hline
\end{tabular}

4 cases, respectively). Aortic stenosis was the least common lesion, being present in 2 cases only, both men, associated in one subject with aortic incompetence and in another with aortic incompetence and mitral incompetence.

Six out of these 48 subjects with rheumatic heart disease had a recurrence of rheumatic fever at the time of the study, seen at home or in the hospital. Four out of these, between the ages of 10 and 12 years, had mitral incompetence and showed signs of rheumatic activity in the form of fever, polyarthralgia and, in two, chorea. The other two, aged 13 and 20 years, respectively, showed signs of mitral stenosis, mitral incompetence, and aortic incompetence with subcutaneous nodules and fever in the former and mitral incompetence and aortic incompetence with fever and polyarthralgia in the latter.

Table 3 shows age and sex distribution in cases of pure mitral stenosis. Twenty-five per cent of both male and female subjects with mitral stenosis were below the age of 20 , and in the case of female subjects, below 15 years. One girl aged 15 years and 6 out of the 9 women with mitral stenosis above the age of 20 years had clinical evidence of pulmonary hypertension; 2 of these had tricuspid incompetence, probably functional, and another was in congestive failure. One of the patients with mitral stenosis and tricuspid incompetence was operated upon elsewhere and was seen again in 1970 when 28 weeks' pregnant and with signs of moderately tight mitral stenosis. One man aged 50 had atrial fibrillation. Congestive heart failure was also seen in two 42-year-old subjects, one man with mitral stenosis, insignificant aortic incompetence, and pulmonary hypertension, and one woman with mitral incompetence and a history of six attacks of rheumatic fever.

Table 4 shows the distribution of the cases with pure mitral incompetence. Here, half the subjects, both male and female, were below the age of 20 years.

Cases of aortic valve disease were distributed in all the age-groups.
The prevalence ratio of rheumatic heart disease and rheumatic fever in different economic groups among male and female subjects is shown in the Fig. The prevalence is highest in the lowest economic groups.

\section{Discussion}

Many workers in India have found a male preponderance in their cases of rheumatic heart disease and rheumatic fever, both in adults (Vakil, 1953; Gour, 1957; Datey et al., 1965; Samani and Chandalia, 1965), and in children (Vaishnava, Webb, and Joseph, 1960). Different hospitals where cardiac surgery is being done routinely as at Vellore (Cherian et al., 1964), Bombay (Parulkar et al., 1966), Delhi (Roy et al., 1963), and Chandigarh have uniformly found male subjects forming the majority of their cases of mitral stenosis and mitral valvotomy. On the other hand, Malhotra and Gupta (I963) from Amritsar in the north, Sepaha, Jain, and Jain (1965) from Indore in central India, and Shankar (1968) from Gulbarga in the south found rheumatic heart disease equally common between the sexes, and mitral stenosis, contrary to reports published on mitral valvotomy, more common among women.

TABLE 3 Age and sex distribution of cases of pure mitral stenosis

\begin{tabular}{lllllll}
\hline Age $(y r)$ & $10-15$ & $15 \cdot 1-20$ & $20 \cdot 1-30$ & $30 \cdot 1-40$ & $40 \cdot 1-50$ & Total \\
\hline Male (17,928) & - & I & 2 & - & 1 & 4 \\
Female (15,433) & 3 & - & 6 & 3 & - & 12 \\
Total (33,361) & 3 & I & 8 & 3 & 1 & 16 \\
\hline
\end{tabular}

TABLE 4 Age and sex distribution of cases of pure mitral incompetence

\begin{tabular}{llllllc}
\hline Age $(y r)$ & $10-15$ & $15 \cdot 1-20$ & $20 \cdot 1-30$ & $30 \cdot 1-40$ & $40 \cdot 1-50$ & Total \\
\hline Male (17,928) & 3 & - & 3 & - & 1 & 7 \\
Female (15,433) & 3 & 4 & 2 & 1 & 2 & 12 \\
Total $(33,361)$ & 6 & 4 & 5 & 1 & 3 & 19 \\
\hline
\end{tabular}


Banerjea (1956) from Calcutta (from where Chatterjee and Das, 1968, found a ratio of $7: 3$ in favour of male subjects in their cases of mitral valvotomy) and Joshi, Khamar, and Damany (1965) from Ahmadabad in the west of India confirmed this, and found rheumatic heart disease much more common among women than men.

It is doubtful that the sex incidence of rheumatic heart disease and mitral stenosis in our country is any different from that in the west where both are more common among women (Wood, 1954; Dubost, Blondeau, and Piwnica, 1962; Friedberg, 1966). This is further supported by the results of the present survey.

The clue to this discrepancy is provided by the figures of hospital utilization by men and women in India. Though the last census in 196I showed that women were only slightly less in number than men in India (1000 to 94I) and in composite Punjab (I000 to 864) (India, 1969), the beds provided for them in hospitals all over the country, apart from obstetric beds, are one-third to two-thirds the number provided for men. In the Nehru Hospital of the P.G.I., the male to female attendance ratio in the medical outpatient department is 1000:688 and in the cardiac clinic, 1000 to 583 . Even in the case of diabetes mellitus, where a higher prevalence has been shown among women in Chandigarh by a similar house-to-house survey (Berry et al., 1966), the clinic registration of new female cases is less than half that of male cases. More significantly, for every known case of diabetes there were two unknown cases, often severe and complicated, among women, while the ratio was reversed among men. It is interesting to note, too, that figures based on hospital data have led to the claim that diabetes mellitus in India shows a peculiar predilection for men (Ajgaonkar and Sathe, 1960). Lesser health consciousness among women, less strenuous physical exertion in schools and elsewhere, fear of adverse effect on prospects of marriage, and on the inlaws in the married, ability to slow the pace of household work, shyness, and reluctance to get examined by male doctors, are some of the factors that tend to delay the unmasking of the disease in women besides comparative ignorance and poor medical facilities. The effect of pregnancy and labour in bringing out the disability may be missed as part of their usual high morbidity and mortality here. Even when the diagnosis is known or suspected, because of the fear of confirmation of the heart disease and operation on the heart, hospital is avoided. All these factors play a greater role in the poor

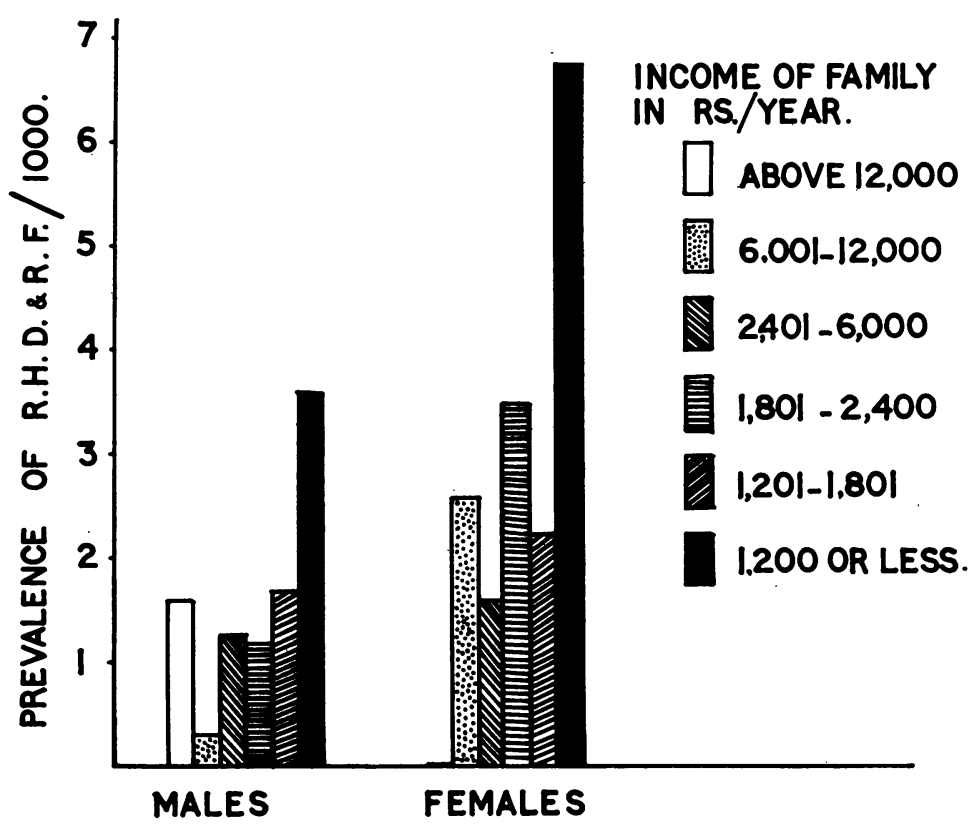

FIG. The prevalence/I0oo of rheumatic heart disease and rheumatic fever in male and female subjects in different economic groups according to the income of the family in Rs./year ( $£ \mathrm{I}=$ approximately I8 Rs.).

and the lower middle classes to whom the majority of these cases belong.

It is probable that the alleged lower prevalence of mitral stenosis among women in other Eastern countries like Pakistan (Ibrahim, 1957) and Egypt (Eissa and Sayed, 1970) also is due to poor hospital utilization by women, since this conclusion is based only on hospital data in their series and most of the abovementioned factors are operative in these countries to a greater or lesser extent.

Even pure mitral incompetence is twice as common in women as in men. Mitral valve involvement occurs in 84 per cent of men and nearly all the women with rheumatic heart disease, and mitral incompetence and mitral stenosis are nearly equally common, each involving half the cases with rheumatic heart disease, singly or in combination. Aortic valve involvement occurs in a quarter of the cases, in 42 per cent of men and 14 per cent of women with rheumatic heart disease. Aortic regurgitation is frequently the result, associated in a small percentage of men with aortic stenosis.

The alleged rarity of lone mitral incompetence in India is again due to preselection of patients coming to teaching hospitals and surgically oriented centres. Thirty-nine per 
cent of cases with rheumatic heart disease had pure mitral incompetence, 33 per cent pure mitral stenosis, and only 4 per cent pure aortic incompetence. No case of pure aortic stenosis was seen and none with pulmonary valve involvement. In two who had tricuspid incompetence, it was adjudged to be functional in origin.

One-quarter of the cases with mitral stenosis and half the cases with mitral incompetence were below the age of 20 years, the socalled juvenile group. Juvenile mitral stenosis has been previously noted in India in the same proportions (Vaishnava et al., 1960; Roy et al., 1963) as well as in other eastern countries (Ibrahim, I957; Al-Bahrani et al., I966; Eissa and Sayed, 1970). Juvenile mitral incompetence has not previously received much attention, since no satisfactory surgical operation is available for it and the patients are treated either by general practitioners or as outpatients only in the hospitals.

In women, not only did mitral stenosis occur earlier - 3 out of 12 against none out of 4 in the ro to 15 year age-group - but also it is more often likely to be complicated by pulmonary hypertension. Seven of the I2 female subjects with pure mitral stenosis had clinical evidence of pulmonary hypertension and 2 of these had tricuspid incompetence and one had congestive cardiac failure against none among the 4 male subjects. Paul Wood (I954) also found a higher prevalence of pulmonary hypertension among women with mitral stenosis.

The prevalence of rheumatic heart disease and rheumatic fever is almost equal in the sexes below the age of 15 but it rises in women in the child-bearing age of 15 to 40 years, indicating even in the absence of a longitudinal study for incidence of new cases, that probably fresh attacks of rheumatic fever continue to occur and cause rheumatic heart disease in women in adult life, probably because of the accelerating influence of pregnancy.

The largest proportion of cases in both sexes came from the lowest income groups. Though the differences are not statistically significant except between the prevalences among the highest and the lowest socioeconomic classes, a clear trend of increasing prevalence with fall in economic standards is seen in the whole group, as well as in both sexes separately. It lends support to the views of White (1953), Stamler (1962), and others that rheumatic heart disease is a social ailment, the incidence of which is increased by poverty and overcrowding and decreased by improvement in living standards.
About 62 per cent of the cases of rheumatic heart disease gave a history suggestive of rheumatic fever. Roy et al. (1963) found it in 68 per cent of their I7I juvenile cases of mitral stenosis and Malhotra and Gupta (1963) found it in 54 per cent of their 1745 cases. Six of the 48 cases with rheumatic heart disease had symptoms and signs suggestive of rheumatic activity and recurrence. This frequency of antecedent history of rheumatic fever and rheumatic recurrences is of the same order as seen by workers in the west (Wood, 1956) and goes against the belief propagated by some workers that in India there is a low rate of acute rheumatic fever and a high rate of valvular heart disease (Padmavati, 1965). The commonest combination was polyarthritis, polyarthralgia, and fever, though this is a weak combination of Modified Jones' criteria (World Health Organization, 1966) for diagnosis of rheumatic fever. A history of chorea was present in 6 cases ( 5 out of those with rheumatic heart disease), and hence was not as uncommon as believed by Roy et al. (I963) and Malhotra and Gupta (I963). Subcutaneous nodules also are not as uncommon here as has been made out. Erythema marginatum like scarlatinal rash in Streptococcus pyogenes tonsillitis is almost never seen here, though its rarity also may be due partly to its transitory nature and masking on a dark skin.

One child with chorea and a history of recurrent sore throat has been included in the 6 cases in which there was only a history suggestive of rheumatic fever. This is a departure from the established use of 2 major or I major and 2 minor Modified Jones' criteria for diagnosis of rheumatic fever. Similarly, inclusion of cases of polyarthralgia or polyarthritis with fever may seem justified only in retrospect in those with rheumatic heart disease, as enough evidence suggestive of past rheumatic fever but is against the established tenet. Mayer et al. (1963) considered the presence of only one of the major criteria sufficient for the diagnosis of rheumatic fever. Feinstein and Spagnuolo (I962) found 4 patterns of presentation of acute rheumatic fever, namely febrile arthritis, febrile arthralgia, chorea, and carditis. In the first two, clinical and immunological evidence of recent Streptococcus pyogenes infection is nearly always present. It is submitted that with the changing picture of rheumatic fever, our increased knowledge of the role of Streptococcus pyogenes infection, and the effectiveness of sulphonamides or penicillin prophylaxis in preventing recurrences of rheumatic fever, and hence cardiac damage, Jones' criteria should 
be liberalized to include unexplained cases of febrile arthritis, chorea, and, even more common, febrile arthralgia, particularly if evidence of recent infection by Streptococcus pyogenes is available. Sulphonamides or penicillin prophylaxis started early in such cases may prevent the severe cardiac damage that is seen so often in these eastern countries where the disease is still poorly controlled and socioeconomic conditions in the vast majority are such as can only promote the disease.

The prevalence of rheumatic fever and rheumatic heart disease was $I \cdot 23$ per thousand among male subjects, 2.07 per thousand among female subjects, and $\mathrm{I} \cdot 62$ per thousand (S.E. $=0.22)$ in the total population $(P=0.06)$. There is no prevalence survey in India or elsewhere, but it is unlikely that the prevalence of rheumatic fever and rheumatic heart disease is less in other areas, as Chandigarh is less overcrowded than most other towns in the country. Since there has been a rapid decline in the incidence as well as the severity of fresh cases of rheumatic fever in the majority of well-developed nations (White, I953; Mayer et al., 1963; Massel, Amezcua, and Pelargonio, 1964; Besterman, 1970), any distant data will not be comparable. School medical examinations may provide some data, but Lee (1958) has shown how ineffective these can be. Results of surveys of schoolchildren in Simla by Devi Chand (1959) in India and by Maresh, Dodge, and Litchy (1952) and Morton, Huhn, and Litchy (1967) in Colorado are not comparable with the present study because of the known higher prevalence of the disease in hilly country. Stamler's (1962) results of less than 2 per thousand in elementary public schools in Chicago are comparable to a prevalence of 2.8 per thousand in children aged Io to 15 years here, but Puddu (1962), whose 3 out of 4 school surveys were done before 1953 when the prevalence of rheumatic fever was still high in most parts of Europe, found prevalence rates of 0.77 to 2 per cent in Italian children.

This study has shown how important it is to conduct such a prevalence survey to find out the epidemiological truth about a disease and its different clinical patterns and how fallacious it can be to depend upon teaching hospital and clinic data alone. Further, it has revealed a large reservoir of patients with rheumatic fever and rheumatic heart disease, probably all over India, among young women who need early diagnosis, prevention of recurrences by chemoprophylaxis, and treatment. Many of these will need mitral valvotomy. Middle schools may be considered as the obvious and simplest means of detecting and bringing help to a large proportion of these persons but if it is appreciated that only about a third of the children in India of II to I4 years go to school (India, 1969), and this proportion is likely to be lower in the poorer and middle classes, any case detection will need much greater effort and organization than vitalizing school medical services.

If this is true also of other eastern countries like Egypt, Pakistan, and Ceylon, as it is believed to be, there is immense scope for a concerted and fruitful drive by the medical services there.

This work was carried out under a financial grant from the I.C.M.R. to which the author is grateful. Also, it is a testimony to the hard work of field workers, Drs. A. Luthra, P. Kaur, and P. Chhokar, and social workers, Iqbal Singh and S. K. Gambhir.

\section{References}

Ajgaonkar, S. S., and Sathe, R. V. (1960). Incidence and aetiology of diabetes mellitus. Fournal of the Association of Physicians of India, 8, 265.

Al-Bahrani, I. R., Thamer, M. A., Al-Omeri, M. M., and Al-Naaman, Y. D. (I966). Rheumatic heart disease in the young in Iraq. British Heart fournal, 28, 824 .

Banerjea, J. C. (1956). A clinical study of rheumatic heart disease. Indian Heart fournal, 8, 39.

Berry, J. N., Chakravarty, R. N., Gupta, H. D., and Malik, K. (1966). Prevalence of diabetes mellitus in a north Indian town. Indian fournal of Medical Research, 54, 1025 .

Besterman, E. (1970). Editorial: The changing face of acute rheumatic fever. British Heart fournal, 32, 579.

Chatteriee, J., and Das, M. M. (1968). A brief analysis of cases of mitral valvotomy. Indian Heart fournal, $20,447$.

Cherian, G., Vytilingam, K. I., Sukumar, I. P., and Gopinath, N. (1964). Mitral stenosis - The interrelated factors and their relation to the results and follow up after valvotomy. Indian Heart fournal, 16, 275 .

Datey, K. K., Sardesai, H. V., Bhandarkar, S. D., and Joshi, N. K. (1965). The incidence of various aetiologies of heart disease in Bombay. Indian Heart fournal, 17, 293.

Devi Chand (1959). Etiology and incidence of heart disease in India with special reference to acquired valvular lesions. Indian Heart fournal, 11 , 117.

Dubost, Ch., Blondeau, Ph., and Piwnica, A. (I962). Instrumental dilatation using the transatrial approach in the treatment of mitral stenosis - A survey of 1000 cases. Fournal of Thoracic and Cardiovascular Surgery, 44, 392.

Eissa, A., and Sayed, H. (1970). Juvenile mitral stenosis in Egypt. Paper presented at the VI World Congress of Cardiology, London.

Feinstein, A. R., and Spagnuolo, M. (1962). The clinical patterns of acute rheumatic fever. A reappraisal. Medicine, 41, 279. 
Friedberg, C. K. (1966). Diseases of the Heart, 3rd ed., p. 1030. Saunders, Philadelphia and London.

Gour, K. N. (1957). A clinical study of rheumatic diseases admitted in the S.N. Hospital, Agra, during ten years from 1946 to 1955. Indian Heart fournal, 9, 100 .

Ibrahim, M. (1957). Rheumatic heart disease in East Pakistan. Diseases of the Chest, 32, 550.

India 1969 (1969). Publication Division, Ministry of Information and Broadcasting, Government of India, Delhi, p. 62.

Joshi, H. D., Khamar, I. M., and Damany, S. J. (1965). Aetiology and incidence of heart diseases in Gujarat. Fournal of the Indian Medical Association, 44,655 .

Lee, J. A. H. (1958). The effectiveness of routine examination of school children. British Medical Fournal, $\mathbf{1}, 573$.

Malhotra, R. P., and Gupta, S. P. (1963). Rheumatic heart disease in Punjab with special emphasis on clinical patterns that differ from those reported abroad. Indian Heart fournal, 15, 107.

Maresh, G. J., Dodge, H. J., and Lichty, J. A. (1952). Incidence of heart disease among Colorado school children. A state wide study. Fournal of the American Medical Association, 149, 802.

Massell, B. F., Amezcua, F., and Pelargonio, S. (1964). Evolving picture of rheumatic fever. Fournal of the American Medical Association, 188, 287.

Mayer, F. E., Doyles, E. F., Herrera, L., and Brownell, K. D. (1963). Declining severity of first attack of rheumatic fever. American Fournal of Diseases of Children, 105, 146.

Morton, W. E., Huhn, L. A., and Litchy, J. A. (1967). Rheumatic heart disease epidemiology. Observations in 17,366 Denver school children. Fournal of the American Medical Association, 199, 879.

Padmavati, S. (1965). Editorial. Special cardiovascular problems in India. Indian Heart fournal, 17, 313.

Parulkar, G. B., Panday, S. R., Kelkar, M. D., and Sen, P. K. (1966). Surgical consideration of mitral stenosis in the young. Paper presented at the $\mathrm{V}$ World Congress of Cardiology, New Delhi.

Puddu, V. (1962). Cardiovascular diseases in Italy. American fournal of Cardiology, 10, 341.

Roy, S. B., Bhatia, M. L., Lazaro, E. J., and Ramalingaswami, V. (1963). Juvenile mitral stenosis in India. Lancet, 2, 1193.

Samani, O. T., and Chandalia, H. B. (1965). Rheumatic heart disease in Bombay - a study of 917 cases. Indian Heart fournal, 17, 283.

Sepaha, G. C., Jain, S. R., and Jain, I. M. (1965). Rheumatic heart disease in Madhya Pradesh - a report of 1016 cases. Indian Heart fournal, 17, 276.

Shankar, P. S. (1968). Cardiovascular disease: its morbidity and mortality in Northern Mysore State. Indian Heart fournal, 20, 423.

Stamler, J. (1962). Cardiovascular diseases in the United States. American fournal of Cardiology, 10, 319.

Vaishnava, S., Webb, J. K. G., and Joseph, C. (1960). Juvenile rheumatism in S. India. Indian fournal of Child Health, 9, 290.

Vakil, R. J. (1953). A study of 655 cases of valvular heart disease in India. Indian Heart fournal, 5, 199.

White, P. D. (1953). Changes in relative prevalence of various types of heart disease in New England. Contrast between 1925 and 1950. Fournal of the American Medical Association, 152, 303.

Wood, P. (1954). An appreciation of mitral stenosis. British Medical fournal, 1, 1051, 1113.

Wood, P. (1956). Diseases of the Heart and Circulation, and ed. Eyre and Spottiswoode, London.

World Health Organization (1966). Prevention of rheumatic fever. World Health Organization, Technical Report Series, No. 342.

Requests for reprints to Professor J. N. Berry, Department of Cardiology, Postgraduate Institute of Medical Education and Research, Chandigarh, India. 